Article

\title{
Two Interpenetrated Zn(II) Coordination Polymers: Synthesis, Topological Structures, and Property
}

\author{
Zi-Wei He, Chang-Jie Liu, Wei-Dong Li, Shuai-Shuai Han and Shui-Sheng Chen *(D) \\ School of Chemistry and Chemical Engineering, Fuyang Normal University, Fuyang 236041, China; \\ heziwei990208@tom.com (Z.-W.H.); liuchangjie990519@tom.com (C.-J.L.); lwd18856859717@tom.com (W.-D.L.); \\ hanshuaishuai@tom.com (S.-S.H.) \\ * Correspondence: fyuniv@163.com; Tel.: +86-558-259-5836
}

Received: 1 November 2019; Accepted: 14 November 2019; Published: 17 November 2019

\begin{abstract}
Two interpenetrated coordination polymers (CPs) $\left\{\left[\mathrm{Zn} 1(\mathrm{~L})\left(\mathrm{NO}_{2} \mathrm{pbda}\right)\right]_{\mathrm{n}}\left[\mathrm{Zn} 2(\mathrm{~L})\left(\mathrm{NO}_{2} \mathrm{pbda}\right)\right]\right.$ $\mathrm{n}\}(\mathbf{1})$ and $[\mathrm{Zn}(\mathrm{L})(\mathrm{Brpbda})]_{\mathrm{n}}(\mathbf{2})$ were prepared by reactions of zinc sulfate heptahydrate with $\mathrm{N}$-donor ligands of 1,4-di(1H-imidazol-4-yl)benzene ( $\mathrm{L}$ ) and auxiliary carboxylic acids of nitroterephthalic acid $\left(\mathrm{H}_{2} \mathrm{NO}_{2}\right.$ pbda) and 2,5-dibromoterephthalic acid $\left(\mathrm{H}_{2} \mathrm{Brpbda}\right)$, respectively. The structures of the $\mathrm{CPs}$ were characterized by Fourier-Transform Infrared (IR) spectroscopy, elemental analysis, and single-crystal X-ray diffraction. The coordination polymer 1 has two different $(4,4)$ sql 2D layer structures based on the $\left[\mathrm{Zn}(\mathrm{L})\left(\mathrm{NO}_{2} \mathrm{pbda}\right)\right]$ moiety, which results in inclined interpenetration with a $2 \mathrm{D}$ $+2 \mathrm{D} \rightarrow 3 \mathrm{D}$ architecture, while the $\mathrm{CP} 2$ exhibits a 3-fold interpenetrating $\mathbf{d m p}$ network. The diffuse reflectance spectra are also investigated for the CPs $\mathbf{1}$ and $\mathbf{2}$.
\end{abstract}

Keywords: coordination polymers; structures; diffuse reflectance spectra

\section{Introduction}

The design of metal-organic coordination polymers (CPs), as one of the most active research areas, has acquired great attention in recent years, due to their intriguing structures and significant applications [1-7]. Recently, luminescent coordination polymers have been widely employed to detect guest molecules with high sensitivity and selectivity. For example, two $C P s,\left\{\left[\mathrm{Cd}_{2} \mathrm{~L}_{2}\left(\mathrm{H}_{2} \mathrm{O}\right)_{4}\right] \cdot \mathrm{H}_{2} \mathrm{O}\right\}_{n}$ and $\left\{\left[\mathrm{Zn}_{2} \mathrm{~L}_{2}\left(\mathrm{H}_{2} \mathrm{O}\right)_{4}\right] \cdot \mathrm{H}_{2} \mathrm{O}\right\}_{\mathrm{n}}\left(\mathrm{H}_{2} \mathrm{~L}=5\right.$ - $(1 \mathrm{H}-1,2,4$-triazol-1-yl)isophthalic acid), can serve as highly selective and sensitive fluorescent probes toward $\mathrm{Cr}^{\mathrm{VI}}$-anions $\left(\mathrm{CrO}_{4}{ }^{2-}\right.$ and $\left.\mathrm{Cr}_{2} \mathrm{O}_{7}{ }^{2-}\right)$ [8]. In crystal engineering, the most important factors in assembling desirable $\mathrm{CPs}$ are the rational choosing of the bridging ligand and metal centers; in addition, other reaction conditions, such as solvent, temperature, $\mathrm{pH}$ value, and the nature of anions, can affect the resulting framework [9-13]. It should be mentioned that the length, rigidity, functional groups, coordination modes, or substituents of organic ligands can decide the final frameworks of CPs [14,15]. Generally, two important kinds of ligands, including $\mathrm{N}$-donor and O-donor organic compounds, are widely used to construct diverse CPs, due to their various coordination modes and modifiable backbones [16,17]. Noticeably, rigid rod-type ligands, including 4,4/-bipyridine (bpy), terephthalic acid, or their analogues, often act as pillars in building a rich variety of new entangled CPs [18,19], while the flexible ligands have different shapes associated with the trans or gauche conformation, favoring the formation of interesting entanglements [20,21]. More recently, a new type of rigid N-donor ligand, including the 4-imidazolyl group, has been designed by our group, and employed to fabricate porous crystalline materials with good gas adsorption properties [22-34]. Moreover, a series of diverse CPs have been built through the mixed system of imidazole and polycarboxylates $[25,26]$. Taking into account their good compatibility for the N/O donor mixed system, we choose different carboxylic acids with distinct natures, together with the rigid rod-type 1,4-di(1H-imidazol-4-yl)benzene (L) ligand to build novel CPs as our continual 
work. In this contribution, we report two $\mathrm{Zn}(\mathrm{II}) \mathrm{CPs}$ of $\left\{\left[\mathrm{Zn} 1(\mathrm{~L})\left(\mathrm{NO}_{2} \mathrm{pbda}\right)\right]_{\mathrm{n}}\left[\mathrm{Zn} 2(\mathrm{~L})\left(\mathrm{NO}_{2} \mathrm{pbda}\right)\right]_{\mathrm{n}}\right\}$ (1) and $[\mathrm{Zn}(\mathrm{L})(\mathrm{Brpbda})]$ (2) by reactions of zinc sulfate heptahydrate with mixed ligands of $\mathrm{L}$ and nitroterephthalic acid $\left(\mathrm{H}_{2} \mathrm{NO}_{2} \mathrm{pbda}\right)$, and 2,5-dibromoterephthalic acid $\left(\mathrm{H}_{2} \mathrm{Brpbda}\right)$, respectively.

\section{Materials and Methods}

\subsection{Materials and Techniques}

The L organic ligand was synthesized according to the literature [27]. The infrared spectrum was recorded on a Bruker Vector 22 FTIR spectrophotometer (Instrument Inc., Karlsruhe, Germany). Elemental analyses were performed on a PerkinElmer 2400 elemental analyzer (PerkinElmer, Waltham, MA, USA). The UV-vis spectra were recorded using a computer-controlled PE Lambda 900 UV-vis spectrometer (PerkinElmer, USA). Thermogravimetric analyses (TGA) were analyzed by a simultaneous SDT 2960 thermal analyzer (Thermal Analysis Instrument Inc., New Castle, DE, USA). Power X-ray diffraction (PXRD) patterns were measured on a Shimadzu XRD-6000 X-ray diffractometer (Shimadzu Corporation, Kyoto, Japan) with $\mathrm{CuK} \alpha(\lambda=1.5418 \AA)$ radiation.

\subsection{Synthesis of $\left\{\left[\mathrm{Zn} 1(\mathrm{~L})\left(\mathrm{NO}_{2} \mathrm{pbda}\right)\right]_{n}\left[\mathrm{Zn} 2(\mathrm{~L})\left(\mathrm{NO}_{2} \mathrm{pbda}\right)\right]_{n}\right\}$ (1)}

Mixtures of $\mathrm{ZnSO}_{4} \cdot 7 \mathrm{H}_{2} \mathrm{O}(28.7 \mathrm{mg}, 0.1 \mathrm{mmol}), \mathrm{L}(21.2 \mathrm{mg}, 0.1 \mathrm{mmol}), \mathrm{H}_{2} \mathrm{NO}_{2}$ pbda $(21.1 \mathrm{mg}$, $0.1 \mathrm{mmol})$, and $\mathrm{H}_{2} \mathrm{O}(10 \mathrm{~mL})$ were adjusted to $\mathrm{pH}=7$ with an $\mathrm{NaOH}$ solution $\left(0.2 \mathrm{~mol} \mathrm{~L}^{-1}\right)$, and were placed in a $25 \mathrm{~mL}$ Teflon-lined container and heated to $160^{\circ} \mathrm{C}$ for $72 \mathrm{~h}$. Brown block crystals of 1 were collected, with a yield of $69 \%$, at room temperature. Anal. calcd for $\mathrm{C}_{20} \mathrm{H}_{13} \mathrm{~N}_{5} \mathrm{O}_{6} \mathrm{Zn}(\%): \mathrm{C}, 49.56 ; \mathrm{H}$, 2.70; N, 14.45. Found: C, 49.38; H, 2.56; N, 14.62. IR: 3447 (w), 3141 (w), 1628 (vs), 1528 (s), 1488 (m), $1377(\mathrm{~m}), 1346(\mathrm{vs}), 1264(\mathrm{w}), 1179(\mathrm{w}), 1124(\mathrm{w}), 1073(\mathrm{w}), 948(\mathrm{w}), 837(\mathrm{~m}), 816(\mathrm{~m}), 785(\mathrm{w}), 651(\mathrm{w})$, $612(w), 521(w), 489(w), 421(w)$.

\subsection{Synthesis of $\left[\mathrm{Zn}_{2}(L)(B r p b d a)_{2}\right]_{n}(2)$}

The same synthetic method as above was used, except that $\mathrm{H}_{2} \mathrm{NO}_{2}$ pbda was replaced by $\mathrm{H}_{2}$ Brpbda (32.4 mg, $0.01 \mathrm{mmol}$ ). Brown block crystals of 2 were obtained (yield: 61\%). Anal. calcd for $\mathrm{C}_{20} \mathrm{H}_{10} \mathrm{Br}_{2} \mathrm{~N}_{4} \mathrm{O}_{4} \mathrm{Zn}(\%): \mathrm{C}, 40.34 ; \mathrm{H}, 1.69 ; \mathrm{N}, 9.41$. Found: $\mathrm{C}, 40.19 ; \mathrm{H}, 1.75 ; \mathrm{N}, 9.29$. IR: 3465 (m), 3386 (m), $3126(\mathrm{~m}), 2856(\mathrm{~m}), 1638(\mathrm{~s}), 1581(\mathrm{~s}), 1545(\mathrm{~s}), 1489(\mathrm{~m}), 1412(\mathrm{~s}), 1359(\mathrm{~m}), 1272(\mathrm{w}), 1182(\mathrm{~m}), 1172$ (m), $1145(\mathrm{~m}), 1132(\mathrm{~s}), 1081(\mathrm{~m}), 968(\mathrm{~m}), 838(\mathrm{~m}), 818(\mathrm{~s}), 798(\mathrm{~m}), 679(\mathrm{~m}), 648(\mathrm{~m}), 628(\mathrm{w}), 530(\mathrm{w})$, $459(\mathrm{w})$.

\subsection{Crystallographic Data Collection and Refinements}

The data collection for CPs 1-2 was carried out on a Bruker Smart Apex CCD area-detector diffractometer. The diffraction data and structural analysis were integrated using the SAINT program and the $S A D A B S$ program, and anisotropically, on $F^{2}$ by the full-matrix least-squares technique, respectively [28-30]. The details of the crystal parameters are summarized in Table 1; selected bond lengths and angles are listed in Table S1. CCDC: 1959065, 1959064 for $\mathbf{1}$ and $\mathbf{2}$. The atoms of C, O, and $\mathrm{Br}$ for $\mathrm{CP} 2$ are disordered and split into (C5, C5B), (C6A, C6B), (C7A, C7B), (C8A, C8B), (C9A, C9B), (C10A, C10B), (O1A, O1B), (O2A, O2B), and (Br1A, Br1B). Copy of the data can be obtained free of charge on application to CCDC, 12 Union Road, Cambridge CB2 1EZ, UK (Fax: +44-1223-336-033; E-Mail: deposit@ccdc.cam.ac.uk). 
Table 1. Crystallographic data and structure refinement details for coordination polymers (CPs) $\mathbf{1}$ and 2.

\begin{tabular}{ccc}
\hline & $\mathbf{1}$ & $\mathbf{2}$ \\
\hline Empirical formula & $\mathrm{C}_{20} \mathrm{H}_{13} \mathrm{~N}_{5} \mathrm{O}_{6} \mathrm{Zn}$ & $\mathrm{C}_{20} \mathrm{H}_{10} \mathrm{Br}_{2} \mathrm{~N}_{4} \mathrm{O}_{4} \mathrm{Zn}$ \\
Formula weight & 484.72 & 595.51 \\
Temperature/K & $296(2)$ & $296(2)$ \\
Crystal system & Triclinic & Orthorhombic \\
Space group & $P 1$ & $P$ nna \\
$a / \AA$ & $9.037(2)$ & $11.0101(10)$ \\
$b / \AA$ & $9.141(2)$ & $14.6802(14)$ \\
$c / \AA$ & $12.948(3$ & $14.8721(13)$ \\
$\alpha /^{\circ}$ & $107.832(3)$ & 90 \\
$\beta /^{\circ}$ & $95.123(3)$ & 90 \\
$\gamma /{ }^{\circ}$ & $108.233(3)$ & 90 \\
$V\left(\AA^{3}\right)$ & $946.6(4)$ & $2403.8(4)$ \\
$\mathrm{Z}$, Dcalc/(Mg/m & $4,1.646$ \\
$F(000)$ & $2,1.701$ & 1160 \\
$\theta$ range $/{ }^{\circ}$ & 492 & $3.59-25.01$ \\
Reflections collected & $1.69-25.99$ & 26144 \\
Independent reflections & 7131 & 2088 \\
Goodness-of-fit on $F^{2}$ & 5942 & 1.094 \\
$R_{1}[I>2 \sigma(I)]^{\mathrm{a}}$ & 0.997 & 0.0989 \\
$w R_{2}[I>2 \sigma(I)]^{\mathrm{b}}$ & 0.0398 & 0.2401 \\
${ }^{\mathrm{a}} R_{1}=\left.\Sigma|| F_{\mathrm{o}}|-| F_{\mathrm{c}}|/ \Sigma| F_{\mathrm{o}}\left|{ }^{\mathrm{b}} w R_{2}=\right| \Sigma w\left(\left|F_{\mathrm{o}}\right|^{2}-\left|F_{\mathrm{c}}\right|^{2}\right)|/ \Sigma| w\left(F_{\mathrm{o}}\right)^{2}\right|^{1 / 2}$, where $w=1 /\left[\sigma^{2}\left(F_{\mathrm{o}}{ }^{2}\right)+(a P)^{2}+b P\right] . \mathrm{P}=\left(F_{\mathrm{o}}{ }^{2}+2 F_{\mathrm{c}}{ }^{2}\right) / 3$.
\end{tabular}

\section{Results}

\subsection{Structural Descriptions}

\subsubsection{Structure of $\left\{\left[\mathrm{Zn} 1(\mathrm{~L})\left(\mathrm{NO}_{2} \mathrm{pbda}\right)\right]_{\mathrm{n}}\left[\mathrm{Zn} 2(\mathrm{~L})\left(\mathrm{NO}_{2} \mathrm{pbda}\right)\right]_{\mathrm{n}}\right\}$ (1)}

Single-crystal structural analysis reveals that $\mathrm{CP} 1$ crystallizes in a monoclinic form with space group $P 1$ (Table 1). The asymmetric unit has two sets of $\left[\mathrm{Zn}(\mathrm{L})\left(\mathrm{NO}_{2} \mathrm{pbda}\right)\right]$ units, and each unit includes a distinct $\mathrm{Zn}(\mathrm{II})$ atom, one $\mathrm{L}$ ligand, and one $\mathrm{NO}_{2} \mathrm{pbda}^{2-}$. Both of the $\mathrm{Zn}$ (II) atoms possess a $\mathrm{N}_{2} \mathrm{O}_{2}$ donor set, forming 4-coordinated tetrahedral coordination geometry (Figure 1a). The $\mathrm{Zn}-\mathrm{O}$ bond distances range from 1.939(3) to 2.015(3) $\AA$ and the $\mathrm{Zn}-\mathrm{N}$ bond distances range from 1.980(4) to 2.000(4) $\AA$; the coordination angles around $\mathrm{Zn}(\mathrm{II})$ range from $94.83(14)^{\circ}$ to $128.61(17)^{\circ}$ (Table S1). Noticeably, in each independent set of $\left[\mathrm{Zn}(\mathrm{L})\left(\mathrm{NO}_{2} \mathrm{pbda}\right)\right]_{n}$, the $\mathrm{NO}_{2} \mathrm{pbda}^{2-}$ ligands act as linear ligands to link two $\mathrm{Zn}$ (II) atoms by the opposite carboxylate groups in the $\mu_{1}-\eta^{1}: \eta^{0}$-monodentate mode, forming a one-dimensional (1D) chain $\left[\mathrm{Zn}\left(\mathrm{NO}_{2} \mathrm{pbda}\right)\right]_{\mathrm{n}}$. The linear $\mathrm{L}$ ligands connect $1 \mathrm{D}$ chains into two-dimensional (2D) $\left[\mathrm{Zn}(\mathrm{L})\left(\mathrm{NO}_{2} \text { pbda) }\right]_{\mathrm{n}}\right.$ layers (Figure $1 \mathrm{~b}$ ), which can be considered as $4^{4}$-sql topology, by taking $\mathrm{Zn}(\mathrm{II})$ atoms as 4 -connecting nodes, and the $\mathrm{L}$ and $\mathrm{NO}_{2} \mathrm{pbda}^{2-}$ ligands as 2-connectors. Thus, two L ligands together with two $\mathrm{NO}_{2} \mathrm{pbda}^{2-}$ units, connect four $\mathrm{Zn}$ (II) atoms to afford a $\left[\mathrm{Zn}_{4}(\mathrm{~L})_{2}\left(\mathrm{NO}_{2} \mathrm{pbda}^{2-}\right)_{2}\right]$ square unit, where the lateral $\mathrm{Zn} \cdots \mathrm{Zn}$ distances are around 9.10 and $13.36 \AA$ A. The rhombus has large rectangular windows, which permit inclined interpenetration for these two distinct $\left[\mathrm{Zn}(\mathrm{L})\left(\mathrm{NO}_{2}\right.\right.$ pbda) $]$ layers, with an angle of $66.24^{\circ}$, forming the $2 \mathrm{D}+2 \mathrm{D} \rightarrow 3 \mathrm{D}$ inclined polycatenation framework (Figure 1c,d) [31,32]. 

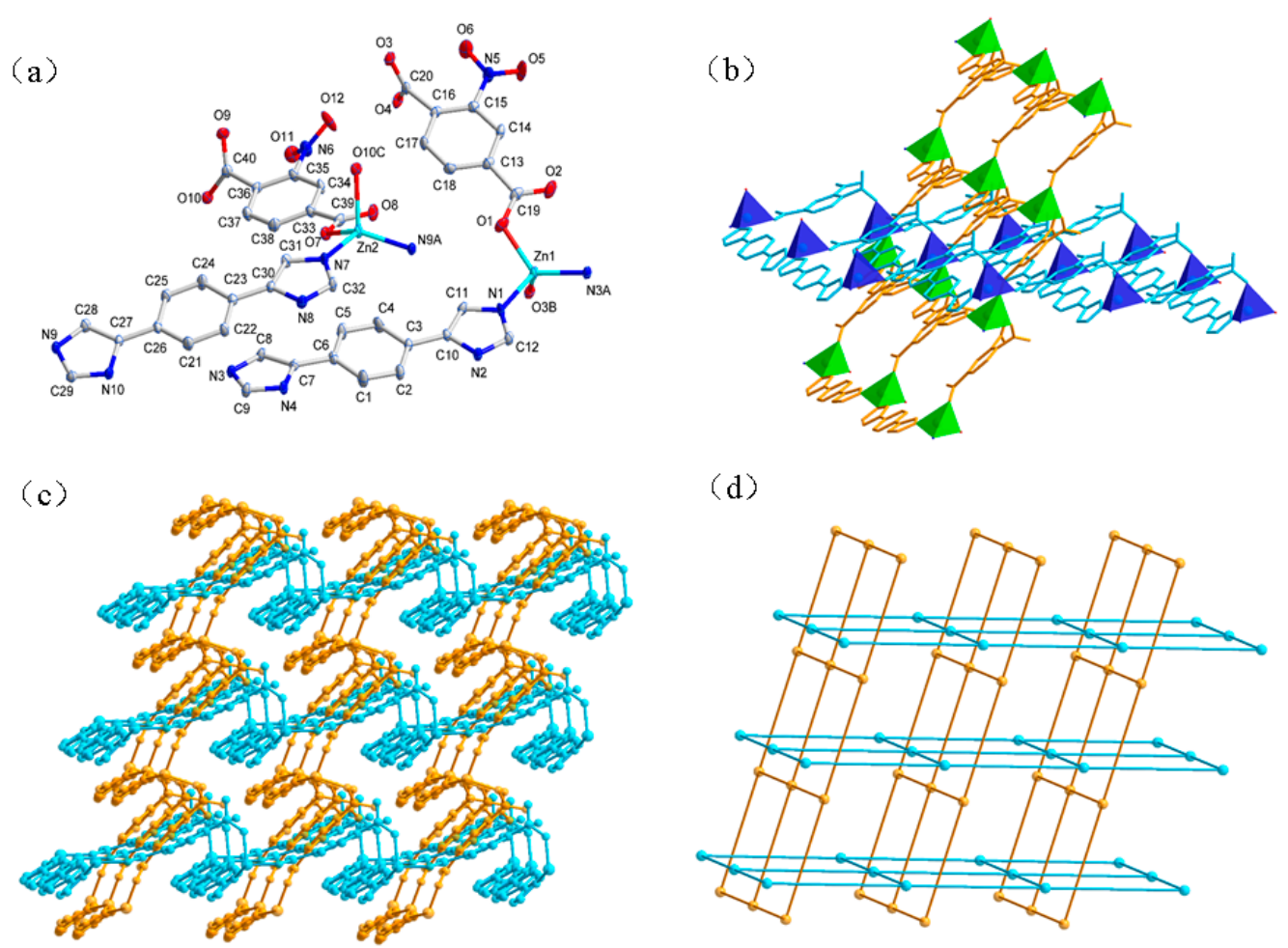

Figure 1. (a) The coordination environment of the $\mathrm{Zn}$ (II) atoms in 1 . Symmetry code: $A \mathrm{x}, 1+\mathrm{y}, 1+\mathrm{z}, \mathrm{B}$ $-1+x, y, z, C x, 1+y$, $z$. (b) $2 D$ polycatenation of 1 . (c) The $3 D$ framework built from $2 D+2 D \rightarrow 3 D$ interpenetration. (d) Schematic representation of inclined interpenetration in $\mathbf{1 .}$

\subsubsection{Structure of $[\mathrm{Zn}(\mathrm{L})(\mathrm{Brpbda})]_{\mathrm{n}}(2)$}

A different $\mathrm{H}_{2} \mathrm{Brpbda}$ acid with a $\mathrm{Br}$ atom substituent group replaced $\mathrm{H}_{2} \mathrm{NO}_{2}$ pbda in the reaction of $\mathbf{1}$, and the new compound of $\mathbf{2}$, possessing 3 -fold interpenetrating $\mathbf{d m p}$ topology was obtained. Complex 2 crystallizes in the orthorhombic $P$ nna space group, quite different from the monoclinic space group, $P 1$, in $\mathbf{1}$. The asymmetric unit includes half of the $[\mathrm{Zn}(\mathrm{L})(\mathrm{Brpbda})]$ units, namely half of a distinct $\mathrm{Zn}$ (II) atom, a Brpbda ${ }^{2-}$ anion, and an L unit, respectively. As shown in Figure 2a, the Zn1 atom is coordinated by two oxygen atoms $(\mathrm{O} 1, \mathrm{O} 1 \mathrm{~A})$ from two different $\mathrm{Brpbda}^{2-}$ anions, and two nitrogen atoms (N3, N3A) of two L ligands, forming distorted tetrahedral coordination geometry. In 2, each Brpbda ${ }^{2-}$ anion links two adjacent $\mathrm{Zn}^{2+}$ ions by two carboxyl groups using the $\mu_{1}-\eta^{1}: \eta^{0}$-monodentate coordination mode, generating a 1D zigzag chain along the $a$ axis (Figure 2b). Similarly, the linear L ligands act as 2-connectors to link Zn(II) atoms to form 1D zigzag chains. As a consequence, these 1D chains are interconnected to afford a 3D coordination framework (Figure 2c). Topologically, both the $\mu_{2}-\mathrm{Brpbda}^{2-}$ anions and the L ligands are linear 2-connectors, while each $\mathrm{Zn}$ (II) atom is a 4-connector to connect the other four $\mathrm{Zn}(\mathrm{II})$ atoms by two Brpbda ${ }^{2-}$ and two L ligands. Thus, the network of 2 is a 4 -connected $\mathbf{d m p}$ net with a $\left(6^{5} \cdot 8\right)$ topology $[33,34]$. Due to the great void of each single net, it permits the inclusion of another two independent equivalent networks, resulting in a 3-fold interpenetrating dmp net (Figure 2d). 
(a)

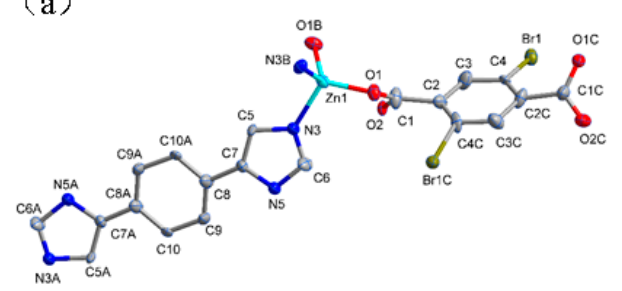

(c)

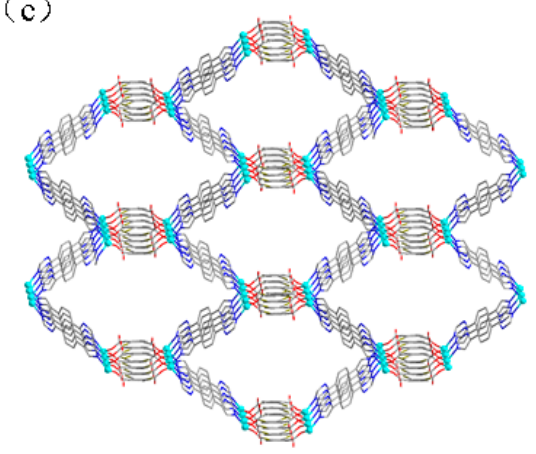

(b)
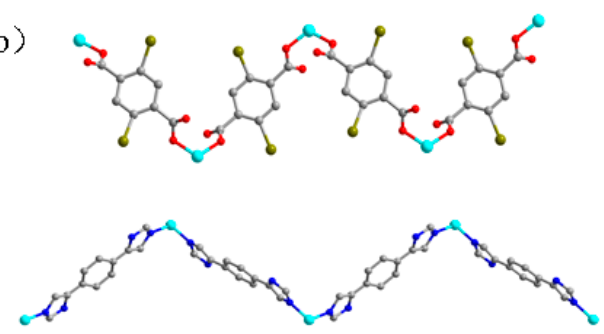

(d)

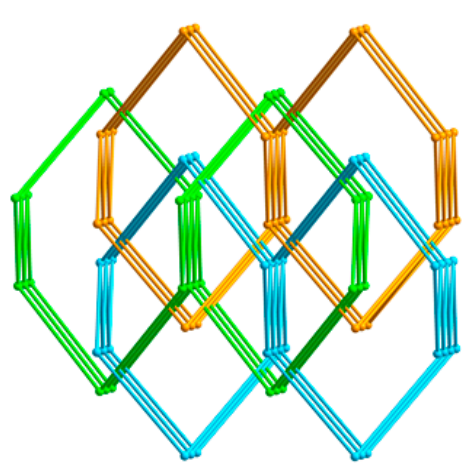

Figure 2. (a) The coordination environment of the $Z n$ (II) atoms in 2. Symmetry code: A $2-x, 1-y, 1-z, B$ $x, 0.5-y, 0.5-z, C 0.5-x,-y$, z. (b) $1 \mathrm{D}$ chains of [Zn(II) $\left(\right.$ Brpbda $\left.\left.^{2-}\right)\right]$ and $[\mathrm{Zn}(\mathrm{II})(\mathrm{L})]$ in 2. (c) $3 \mathrm{D}$ framework of 2. (d) Schematic representation of the 3-fold interpenetrating dmp net with a $\left(6^{5} \cdot 8\right)$ topology.

\subsection{Thermal Analyses and X-Ray Power Diffraction Analyses}

The stability of CPs $\mathbf{1}$ and $\mathbf{2}$ was evaluated by thermogravimetric analysis (TGA); the analysis results are listed in Figure S1. The results of TGA for CPs $\mathbf{1}$ and $\mathbf{2}$ showed no weight losses for the crystalline materials until the frameworks collapses at about 195 and $245^{\circ} \mathrm{C}$ respectively, indicating that the frameworks of compounds 1-2 contain no guest molecules, which is consistent with their structures, as evidenced by the analysis of the crystal structures. The diffraction peaks of as-synthesized CPs 1 and $\mathbf{2}$ fit well with the simulated power X-ray diffraction (PXRD) patterns from single crystal results. The result confirms that the as-synthesized crystalline materials of $\mathbf{1}$ and $\mathbf{2}$ are phase purities, as shown in Figure S2.

\subsection{IR and Diffuse Reflectance Spectra}

IR spectra of CPs 1 and 2 were recorded between 4000 and $400 \mathrm{~cm}^{-1}$. The characteristic peak with vibrational bands, $1638-1528 \mathrm{~cm}^{-1}$, disappear around $1700 \mathrm{~cm}^{-1}$, which means the carboxylic groups are deprotonated. The infrared spectra of $\mathrm{L}$ indicate the prominent characteristic absorption bands at $1528-1489$ and $1270-1124 \mathrm{~cm}^{-1}$, attributed to its aromatic rings [35].

The UV-vis absorption spectra of $\mathbf{1}$ and $\mathbf{2}$ in their solid states were recorded in Figure 3 . The L ligand shows intense absorption peaks ranging from 250 to $300 \mathrm{~nm}$, which belongs to $\pi-\pi^{*}$ transitions [36]. Obviously, the CPs 1 and 2 showed similar absorption bands in the UV region, which correspond to intraligand $\pi \rightarrow \pi^{*}$ and $n \rightarrow \pi^{*}$ transitions. Furthermore, the diffuse reflectance data obtained were transformed into a Kubelka-Munk function to get their band gaps (Eg), which can be employed to evaluate the semiconductivity of the CPs. The values of Eg are estimated as 3.52 and $2.59 \mathrm{eV}$ for CPs 1 and 2 (Figure 4), which were determined by a direct band gap semiconductor: $(\mathrm{Ahv})^{2}=\mathrm{B}(\mathrm{h} v-\mathrm{Eg})$. The values of $\mathrm{Eg}$ for CPs $\mathbf{1}$ and $\mathbf{2}$ are comparatively a little higher than the series of $\mathrm{Ni}(\mathrm{II})$ compounds [37], and the as-synthesized crystalline materials may be optical semiconductors [38]. 


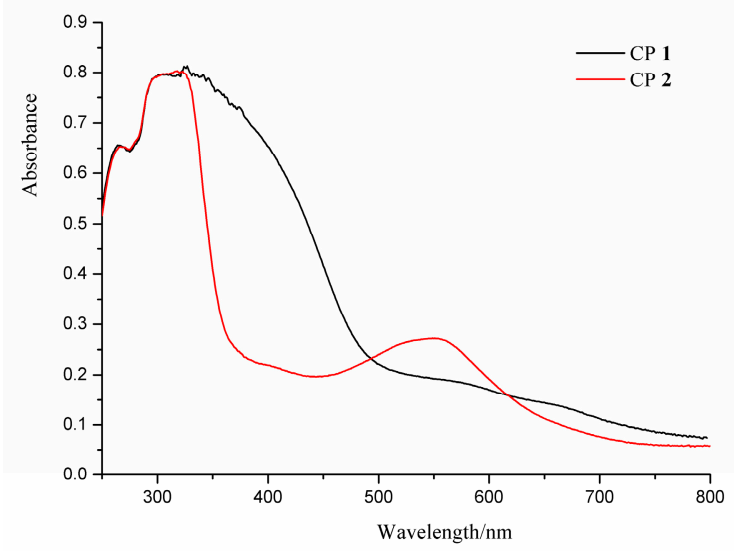

Figure 3. The UV-vis spectra for the CPs 1-2.

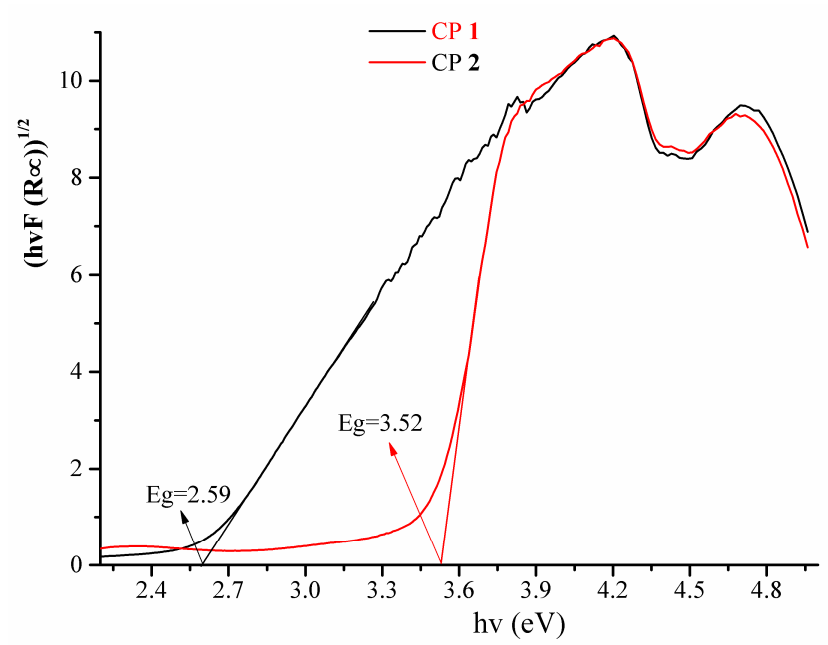

Figure 4. The Eg values for CPs 1-2 treated with the Kumble-Munk function.

\section{Conclusions}

Two interpenetrated $\mathrm{Zn}(\mathrm{II}) \mathrm{CPs}$ based on mixed N-donor and O-donor ligands of $\mathrm{L}$ and aromatic dicarboxylic acid were prepared with reactions of zinc sulfate heptahydrate by hydrothermal reaction. The natures of the different substituent groups of auxiliary dicarboxylic acid ligands make different structures for CPs $\mathbf{1}$ and $\mathbf{2}$. The compounds $\mathbf{1}$ and $\mathbf{2}$ are $2 \mathrm{D}+2 \mathrm{D} \rightarrow 3 \mathrm{D}$-inclined polycatenation structures or 3-fold interpenetrating $\mathbf{d m p}$ networks, due to different substituent groups from nitroterephthalic acid and 2,5-dibromoterephthalic acid. The UV-vis absorption spectra of $\mathbf{1}$ and $\mathbf{2}$ were investigated. The results have further confirmed that the mixed system of N/O-donor ligands is a favorable strategy for building diverse coordination polymers.

Supplementary Materials: The following are available online at http://www.mdpi.com/2073-4352/9/11/601/s1. Figure S1 and S2 represent TGA and PXRD. Selected bond lengths and bond angles are listed in Table S1.

Author Contributions: Z.-W.H. and C.-J.L. did the experiments and analyzed the data. W.-D.L. and S.-S.H. made the measurements. S.-S.C. charged the project.

Funding: Thanks for the funding of the Cooperative Project of Fuyang Government (XDHX201707) and the youth talent program (gxbjZD19).

Conflicts of Interest: The authors declare no conflict of interest.

\section{References}

1. Kang, Y.S.; Lu, Y.; Chen, K.; Zhao, Y.; Wang, P.; Sun, W.Y. Metal-organic frameworks with catalytic centers: From synthesis to catalytic application. Coord. Chem. Rev. 2019, 378, 262-280. [CrossRef] 
2. Fu, H.R.; Wang, N.; Qin, J.H.; Han, M.L.; Ma, L.F.; Wang, F. Spatial confinement of a cationic MOF: A SC-SC approach for high capacity $\mathrm{Cr}(\mathrm{VI})$-oxyanion capture in aqueous solution. Chem. Commun. 2018, 54, 11645-11648. [CrossRef] [PubMed]

3. Zhao, Y.; Wang, L.; Fan, N.N.; Han, M.L.; Yang, G.P.; Ma, L.F. Porous Zn(II)-based metal-organic frameworks decorated with carboxylate groups exhibiting high gas adsorption and separation of organic dyes. Cryst. Growth Des. 2018, 18, 7114-7121. [CrossRef]

4. Yang, X.G.; Ma, L.F.; Yan, D.P. Facile synthesis of 1D organic-inorganic perovskite micro-belts with high water stability for sensing and photonic applications. Chem. Sci. 2019, 10, 4567-4572. [CrossRef]

5. Seidi, F.; Jenjob, R.; Crespy, D. Designing smart polymer conjugates for controlled release of payloads. Chem. Rev. 2018, 118, 3965-4036. [CrossRef]

6. Zhao, Y.; Yang, X.G.; Lu, X.M.; Yang, C.D.; Fan, N.N.; Yang, Z.T.; Wang, L.Y.; Ma, L.F. $\left\{Z_{6}\right\}$ cluster based metal-organic framework with enhanced room-temperature phosphorescence and optoelectronic performances. Inorg. Chem. 2019, 58, 6215-6221. [CrossRef]

7. Cheng, Y.J.; Wang, R.; Wang, S.; Xi, X.J.; Ma, L.F.; Zang, S.Q. Encapsulating $\left[\mathrm{Mo}_{3} \mathrm{~S}_{13}\right]^{2-}$ clusters in cationic covalent organic frameworks: Enhancing stability and recyclability by converting a homogeneous photocatalyst to a heterogeneous photocatalyst. Chem. Commun. 2018, 54, 13563-13566. [CrossRef]

8. Wang, C.X.; Xia, Y.P.; Yao, Z.Q.; Xu, J.; Chang, Z.; Bu, X.H. Two luminescent coordination polymers as highly selective and sensitive chemosensors for $\mathrm{Cr}^{\mathrm{VI}}$-anions in aqueous medium. Dalton Trans. 2019, 48, 387-394. [CrossRef]

9. Han, M.L.; Chang, X.H.; Feng, X.; Ma, L.F.; Wang, L.Y. Temperature and pH driven self-assembly of $\mathrm{Zn}$ (II) coordination polymers: Crystal structures, supramolecular isomerism, and photoluminescence. CrystEngComm 2014, 16, 1687-1695. [CrossRef]

10. Li, X.Q.; Zhou, Z.; Zhang, C.C.; Zheng, Y.H.; Gao, J.W.; Wang, Q.M. Modulation of assembly and disassembly of a new tetraphenylethene based nanosensor for highly selective detection of hyaluronidase. Sens. Actuators B Chem. 2018, 276, 95-100. [CrossRef]

11. Zhou, Z.; Han, M.L.; Fu, H.R.; Ma, L.F.; Luo, F.; Li, D.S. Engineering design toward exploring the functional group substitution in $1 \mathrm{D}$ channels of $\mathrm{Zn}$-organic frameworks upon nitro explosives and antibiotics detection. Dalton Trans. 2018, 47, 5359-5365. [CrossRef] [PubMed]

12. Dong, X.Y.; Si, C.D.; Fan, Y.; Hu, D.C.; Yao, X.Q.; Yang, Y.X.; Liu, J.C. Effect of N-donor ligands and metal ions on the coordination polymers based on a semirigid carboxylic acid ligand: Structures analysis, magnetic properties, and photoluminescence. Cryst. Growth Des. 2016, 16, 2062-2073. [CrossRef]

13. Yang, X.G.; Lu, X.M.; Zhai, Z.M.; Zhao, Y.; Liu, X.-Y.; Ma, L.-F.; Zang, S.-Q. Facile synthesis of micro-scale MOF host-guest with long-last phosphorescence and enhanced optoelectronic performance. Chem. Commun. 2019, 55, 11099-11102. [CrossRef] [PubMed]

14. Roztocki, K.; Jedrzejowski, D.; Hodorowicz, M.; Senkovska, I.; Kaskel, S.; Matoga, D. Effect of linker substituent on layers arrangement, stability, and sorption of Zn-isophthalate/acylhydrazone frameworks. Cryst. Growth Des. 2018, 18, 488-497. [CrossRef]

15. Singh, R.; Bharadwaj, P.K. Coordination polymers built with a linear bis-imidazole and different dicarboxylates: Unusual entanglement and emission properties. Cryst. Growth Des. 2013, 13, 3722-3733. [CrossRef]

16. Guo, X.Z.; Li, J.L.; Shi, S.S.; Zhou, H.; Han, S.S.; Chen, S.S. Synthesis, structure and luminescent property of a $\mathrm{Zn}$ (II) complex with mixed multi-N donor and 2,5-dihydroxy-terephthalic acid ligands. Chin. J. Struct. Chem. 2018, 37, 1117-1124.

17. Cui, Y.; Li, B.; He, H.; Zhou, W.; Chen, B.; Qian, G. Metal-organic frameworks as platforms for functional materials. Acc. Chem. Res. 2016, 49, 483-493. [CrossRef]

18. Wang, S.L.; Hu, F.L.; Zhou, J.Y.; Zhou, Y.; Huang, Q.; Lang, J.P. Rigidity versus flexibility of ligands in the assembly of entangled coordination polymers based on Bi-and tetra carboxylates and N-Donor ligands. Cryst. Growth Des. 2015, 15, 4087-4097. [CrossRef]

19. Wang, S.; Yun, R.; Peng, Y.; Zhang, Q.; Lu, J.; Dou, J.; Bai, J.; Li, D.; Wang, D. A series of four-connected entangled metal-organic frameworks assembled from pamoic acid and pyridine-containing ligands: Interpenetrating, self-penetrating, and supramolecular isomerism. Cryst. Growth Des. 2012, 12, 79-92. [CrossRef] 
20. Chang, X.H.; Qin, J.H.; Ma, L.F.; Wang, J.G.; Wang, L.Y. Two- and three-dimensional divalent metal coordination polymers constructed from a new tricarboxylate linker and dipyridyl ligands. Cryst. Growth Des. 2012, 12, 4649-4657. [CrossRef]

21. Hernández-Maldonado, A.J.; Arrieta-Pérez, R.R.; Primera-Pedrozo, J.N.; Exley, J. Structure of a porous $\mathrm{Cu}_{2}$ (pzdc) ${ }_{2}$ (bpp) (pzdc: Pyrazine-2,3-dicarboxylate, bpp: 1,3-Bis(4-pyridyl)propane) coordination polymer and flexibility upon concomitant hysteretic $\mathrm{CO}_{2}$ adsorption. Cryst. Growth Des. 2015, 15, 4123-4131. [CrossRef]

22. Chen, S.S.; Chen, M.; Takamizawa, S.; Chen, M.S.; Su, Z.; Sun, W.Y. Temperature dependent selective gas sorption of the microporous metal-imidazolate framework $[\mathrm{Cu}(\mathrm{L})]\left[\mathrm{H}_{2} \mathrm{~L}=1,4\right.$-di( $1 \mathrm{H}$-imidazol-4-yl)benzene]. Chem. Commun. 2011, 47, 752-754. [CrossRef] [PubMed]

23. Chen, S.S.; Chen, M.; Takamizawa, S.; Wang, P.; Lv, G.C.; Sun, W.Y. Porous cobalt(II)-imidazolate supramolecular isomeric frameworks with selective gas sorption property. Chem. Commun. 2011, 47, 4902-4904. [CrossRef] [PubMed]

24. Chen, S.S.; Wang, P.; Takamizawa, S.; Okamura, T.A.; Chen, M.; Sun, W.Y. Zinc(II) and cadmium(II) metal-organic frameworks with 4-imidazole containing tripodal ligand: Sorption and anion exchange properties. Dalton Trans. 2014, 43, 6012-6020. [CrossRef] [PubMed]

25. Sun, Y.X.; Sun, W.Y. Zinc(II)- and cadmium(II)-organic frameworks with 1-imidazole-containing and 1-imidazole-carboxylate ligands. CrystEngComm 2015, 17, 4045-4063. [CrossRef]

26. Chen, S.S.; Sheng, L.Q.; Zhao, Y.; Liu, Z.D.; Qiao, R.; Yang, S. Syntheses, structures, and properties of a series of polyazaheteroaromatic core-based $\mathrm{Zn}(\mathrm{II})$ coordination polymers together with carboxylate auxiliary ligands. Cryst. Growth Des. 2016, 16, 229-241. [CrossRef]

27. Have, R.T.; Huisman, M.; Meetsma, A.; van Leusen, A.M. Novel synthesis of 4(5)-monosubstituted imidazoles via cycloaddition of tosylmethyl isocyanide to aldimines. Tetrahedron 1997, 53, 11355-11368. [CrossRef]

28. SAINT; Version 6.2; Bruker AXS, Inc.: Madison, WI, USA, 2001.

29. Sheldrick, G.M. SADABS; University of Göttingen: Göttingen, Germany, 1997.

30. Sheldrick, G.M. SHELXTL; Version 6.10; Bruker Analytical Xray Systems: Madison, WI, USA, 2001.

31. Wang, C.Y.; Wilseck, Z.M.; LaDuca, R.L. 1D + 1D $\rightarrow$ 1D polyrotaxane, 2D + 2D $\rightarrow$ 3D interpenetrated, and 3D self-penetrated divalent metal terephthalate bis(pyridylformyl)piperazine coordination polymers. Inorg. Chem. 2011, 50, 8997-9003. [CrossRef]

32. Chen, S.S.; Li, J.L.; Li, W.D.; Guo, X.Z.; Zhao, Y. Four new transition metal coordination polymers based on mixed 4-imidazole and carboxylate-sulfonate ligands: Syntheses, structures, and properties. J. Solid State Chem. 2019, 277, 510-518. [CrossRef]

33. Xue, L.P.; Li, Z.H.; Ma, L.F.; Wang, L.Y. Crystal engineering of cadmium coordination polymers decorated with nitro-functionalized thiophene-2,5-dicarboxylate and structurally related bis(imidazole) ligands with varying flexibility. CrystEngComm 2015, 17, 6441-6449. [CrossRef]

34. Liu, X.M.; Xie, L.H.; Lin, J.B.; Lin, R.B.; Zhang, J.P.; Chen, X.M. Flexible porous coordination polymers constructed from 1,2-bis(4-pyridyl)hydrazine via solvothermal in situ reduction of 4,4'-azopyridine. Dalton Trans. 2011, 40, 8549-8554. [CrossRef] [PubMed]

35. Zhu, M.A.; Guo, X.Z.; Xiao, L.; Chen, S.S. A new Cd(II) coordination compound based on 4-(1,2,4-Triazol-4-yl)phenylacetic acid: Synthesis, structure and photoluminescence property. Chin. J. Struct. Chem. 2018, 37, 437-444.

36. Shi, Z.; Pan, Z.; Qin, L.; Zhou, J.; Zheng, H. Five new transition metal coordination polymers based on V-shaped bis-triazole ligand with aromatic dicarboxylates: Syntheses, structures, and properties. Cryst. Growth Des. 2017, 17, 2757-2766. [CrossRef]

37. Liu, L.; Huang, C.; Xue, X.; Li, M.; Hou, H.; Fan, Y. Ni(II) coordination polymers constructed from the flexible tetracarboxylic acid and different N-donor ligands: Structural diversity and catalytic activity. Cryst. Growth Des. 2015, 15, 4507-4517. [CrossRef]

38. Hu, Z.Y.; Zhao, M.; Su, J.; Xu, S.; Hu, L.; Liu, H.; Zhang, Q.; Zhang, J.; Wu, J.; Tian, Y. Three coordination polymers based on a star-like geometry $4,4^{\prime}, 4^{\prime \prime}$-nitrilotribenzoic acid ligand and their framework dependent luminescent properties. J. Solid State Chem. 2018, 258, 328-334. [CrossRef]

(C) 2019 by the authors. Licensee MDPI, Basel, Switzerland. This article is an open access article distributed under the terms and conditions of the Creative Commons Attribution (CC BY) license (http://creativecommons.org/licenses/by/4.0/). 